\title{
Analysis on epidemiological characteristics of food poisoning events in Agadir prefecture, Morocco, from 2015 to 2017
}

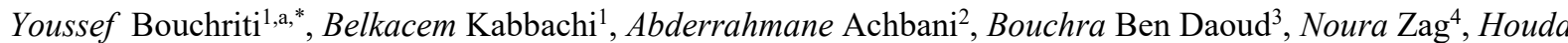 \\ Taoussi $^{5}$, and Sarrah Ezaidi ${ }^{1}$ \\ ${ }^{1}$ Geosciences and Environment Team, Faculty of Sciences of Agadir, Ibn Zohr University, Morocco \\ ${ }^{a}$ Moroccan Ministry of Health, High Institute of Nursing Professions and Technical Health, Agadir, Morocco \\ ${ }^{2}$ Laboratory of Cell Biology and molecular genetics, Faculty of Agadir Sciences, Ibn Zohr University, Agadir, Morocco \\ ${ }^{3}$ Moroccan Ministry of Health, Casablanca University Hospital \\ ${ }^{4}$ Moroccan Ministry of Health, Guelmim Regional Hospital Center \\ ${ }^{5}$ Moroccan Ministry of Health, Taroudannt Delegation
}

\begin{abstract}
Food poisoning is a significant public health problem. The aim of this study was to investigate the epidemiological characteristics of food poisoning events in Agadir prefecture in Morocco. Data on food poisoning events was compiled and analyzed from 2015 to 2017. The food poisoning database was created using Excel software, and the data was classified for statistical analysis. In Agadir prefecture, 11 food poisoning events were recorded over the past three years, involving 163 persons and resulting in two deaths. There were 7 and 4 events in the urban and rural areas, respectively. Females were most exposed (67.5\%). The annual average morbidity rate was $27.2 / 100,000$, the global lethality rate was $1.3 \%$, and an average of 14.8 persons was involved in a poisoning event. Adolescents make up a quarter of the cases. Most cases occurred in closed communities. The foods involved in these poisoning events were eaten raw. The most common food related with poisoning was meat products. Only six events had samples taken for microbiological testing of the food remaining implicated in the outbreak of these events, and the findings revealed that Salmonella and Escherichia coli were identified in four of the six events, while Candida albicans and total coliforms were detected in two of the six events. Foodborne illness prevention and control should be carried out in closed communities by improving food safety supervision, implementing an effective food poisoning early-warning system, and establishing a surveillance, inspection, and early-warning system for food contaminants and foodborne diseases.
\end{abstract}

\section{Introduction}

Foodborne diseases are an important cause of morbidity and mortality. In 2010, they were responsible for 600 million foodborne illnesses and 420,000 deaths globally, and $40 \%$ of the foodborne disease burden was among children under 5 years of age [1]. Every year, an estimated 600 million people, or about one in every ten people in the world, become ill as a result of ingesting contaminated food, with diarrheal diseases being the most frequent kind of illness [2]. They represent a great financial burden on society and represent a public health risk, resulting in acute morbidity and chronic consequences $([3,4])$.

Africa was identified to have the highest burden per population. The Middle East and North Africa region is a particular one of concern [5]. With its frequency and severity, poisoning is a serious public health problem in Morocco. Food poisoning is required to be reported in Morocco, and investigations must be conducted. Indeed, the poison control and pharmacovigilance center of Morocco received 1,371 reports of food poisoning cases in 2019 , with collective cases accounting for $55.8 \%$ of the total. Food poisoning is the third most common cause of food poisoning in Morocco, accounting for $12.5 \%$ of all cases [6]. These diseases were at the top of the list of reported poisoning in Morocco ten years ago [7].

Furthermore, the Moroccan Ministry of Health's Epidemiology and Disease Control Department reports that all sanitary regions are affected, with a clear predominance in urban areas [8].

Poisoning has been the subject of several research in Morocco ([7,9-11]). Food poisoning contributes for a significant percentage of national poisoning cases, according to these studies.

The aim of the study was to analyze the characteristics of food poisoning events documented by Agadir's Prefectural Epidemiology Unit between 2015 and 2017.

* Corresponding author: bouchriti.y.ege@gmail.com 


\section{Material and methods}

This is a three-year retrospective analysis based on data from Agadir's Prefectural Epidemiology Unit between 2015 and 2017. It was of interest to all patients with food poisoning who consulted one of the Agadir prefectural healthcare centers.

Agadir Ida Outanane prefecture belongs to the region of Souss-Massa, its area is 2,297 km², between 9 ${ }^{\circ} 13^{\prime} 10$ and 9 $9^{\circ} 3^{\prime} 30$ degrees West longitude, and $30^{\circ} 56^{\prime} 00$ and $30^{\circ} 20^{\prime} 50$ degrees North latitude, is located in the central west of Morocco [12]. The population is 598,757 persons, there are 506,517 people living in urban areas (84.6\%) and 92,240 persons living in rural areas (15.4\%) [13].

The research period was chosen based on the availability of data from epidemiological investigations of food poisoning events. Each case of food poisoning was recorded using a standard form developed by the Moroccan Ministry of Health's Epidemiology and Disease Control Department.

This form includes information on the event (location, number of events, and number of cases), the suspected foodstuff (category, method of preparation, pathogenic agent, and sampling), and case characteristics (gender, age, hospitalization, death, time and date of consumption).

The frequencies or averages of each investigated variable were calculated using descriptive statistics, allowing us to describe the food poisoning events. Epidemiological (age, gender), temporal and geographical (years, location), evolutionary (death, recovery), and suspicious foodstuffs were all included in the research.

According to the validity of the data collected, was calculated the association measures by OpenEpi tool [14]. Statistical significance was established by a $\mathrm{p}<0.05$ value. Yates' Chi2 test (X2) was used for the comparison between the categorical variables. Relative risk values (RR) and 95\% confidence intervals (CI95\%) were estimated.

\section{Results}

Between 2015 and 2017, 11 food poisoning events were carried over, with 7 of them occurring in urban areas. Despite the fact that just 10 cases were reported in 2015 , the trend for food poisoning events is increasing, even if the cases recorded in 2016 and 2017 are similar (Table 1).

The annual average morbidity rate was $27.2 / 100,000$, the global lethality rate was $1.3 \%$, and an average of 14.8 persons was involved in a poisoning event.

The proportions of female and male cases were $67.5 \%$ and $31.3 \%$, respectively. Two cases missed gender information (accounts for $1.2 \%$ of cases). Females are affected more than males (The sex ratio $\mathrm{M} / \mathrm{F}=0.45$ ).
There were also two male deaths documented. The proportions of cases from urban and rural areas were 76.7 $\%$ and $23.3 \%$, respectively.

Table 1. Food poisoning events, Agadir prefecture, 2015-2017.

\begin{tabular}{|c|c|c|c|c|c|c|c|}
\hline Year & $\begin{array}{c}\text { Even } \\
\text { ts } \\
\text { total } \\
\text { num } \\
\text { ber }\end{array}$ & $\begin{array}{c}\text { Tota } \\
\mathbf{l} \\
\text { deat } \\
\text { hs }\end{array}$ & $\begin{array}{c}\text { Even } \\
\text { ts } \\
\text { perc } \\
\text { enta } \\
\text { ge } \\
\mathbf{( \% )}\end{array}$ & $\begin{array}{c}\text { Case } \\
\text { sotal } \\
\text { num } \\
\text { ber } \\
\text { per } \\
\text { even } \\
\text { ts }\end{array}$ & $\begin{array}{c}\text { Case } \\
\text { s } \\
\text { perc } \\
\text { enta } \\
\text { ge } \\
\mathbf{( \% )}\end{array}$ & $\begin{array}{c}\text { Hos } \\
\text { pital } \\
\text { ized } \\
\text { cases }\end{array}$ & $\begin{array}{c}\text { Perc } \\
\text { enta } \\
\text { ge of } \\
\text { hosp } \\
\text { italiz } \\
\text { ation } \\
\mathbf{( \% )}\end{array}$ \\
\hline 2015 & 3 & 1 & 27.3 & 10 & 6.1 & 6 & 60.0 \\
\hline 2016 & 3 & 0 & 27.3 & 74 & 45.4 & 16 & 21.6 \\
\hline 2017 & 5 & 1 & 45.4 & 79 & 48.5 & 44 & 55.7 \\
\hline Total & 11 & 2 & 100 & 163 & 100 & 66 & 40.5 \\
\hline
\end{tabular}

Half of the cases were between the ages of 20 and 60 , with those under the age of 20 accounting for $40.5 \%$ and those over 60 accounting for $6.7 \%$ (Fig. 1)

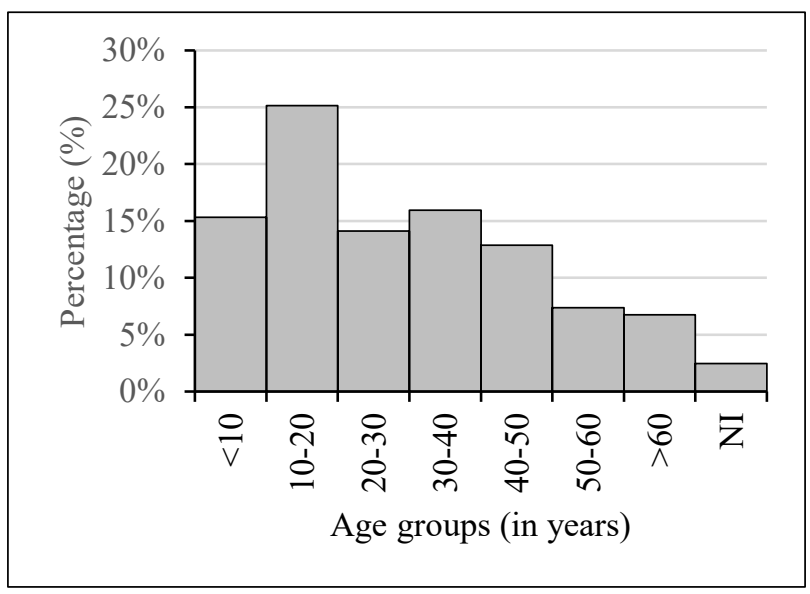

Fig. 1. Age distribution of food poisoning events cases, Agadir prefecture, 2015-2017.

Overall proportion of patients requiring hospitalization was $40.5 \%$, with a ratio of 2.5 (Table 1 ). Furthermore, the proportion of hospitalized patients in $2015(60 \%)$ was greater than in $2016(21.6 \%)$ and 2017 $(55.7 \%)$. Hospitalizations are on the rise in a straight line (positive slope of the regression line). The number of cases and hospitalizations had a positive correlation $(\mathrm{r}=$ 0.92).

In terms of cases per event, cases from the third event of 2016 and those from the second event of 2017 accounted for more than half of the total cases (53.4\%) (Fig. 2).

The mean number of cases per event was 14.8 , the standard deviation was 13.6, and therefore, the case 
values were dispersed around the mean. The distribution of cases was asymmetric to the right of the mean (Pearson's asymmetry coefficient $=2.1$ ).

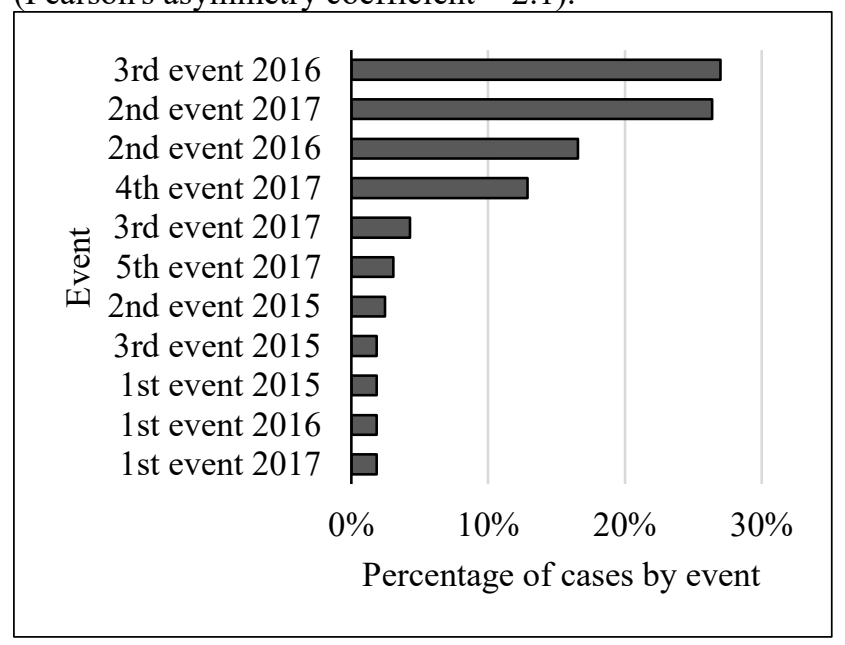

Fig. 2. Percentage distribution of food poisoning cases per event, Agadir prefecture, 2015-2017.

Food poisoning events were mostly caused by the following foods, in decreasing order: meat products (31\%), milk and dairy products $(16.2 \%)$, fruits $(14.5 \%)$, and beverages (14.2\%). Other foodstuffs accounted for $24.1 \%$ (Fig. 3).

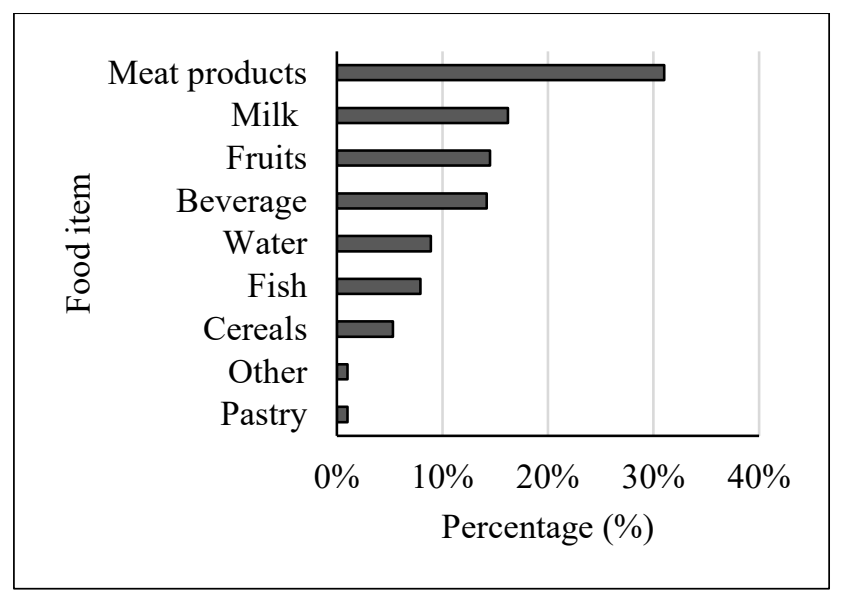

Fig. 3. Distribution of cases food poisoning events by suspected food item(s), Agadir prefecture, 2015-2017.

The items associated to food poisoning outbreaks were mostly served raw $(47.9 \%)$ or cooked $(33.1 \%)$. Also, $15.3 \%$ of these items were combined (both cooked and raw). We've also seen cases when food was delivered in the form of canned or previously chilled meals $(1.8 \%)$.

Closed communities were the primary source of contamination in $93.9 \%$ of food poisoning cases, with the other forms (mass catering and itinerant merchants) accounting for only $6.1 \%$.

Only six events (54.5\%) had samples taken for bacteriological analysis of the residues of the food implicated in the onset of these events. These investigations revealed that Salmonella and Escherichia coli were found in four of the six events, whereas Candida albicans and total coliforms were found in two of the six events.

\section{Discussion}

Food poisoning events were documented in all areas of Morocco, with regional variation. Demographic, geographical, economic, social, and cultural variability can all contribute to this disparity. In the Souss-Massa area, the number of poisoning cases as well as the mortality rate cannot be ignored [15].

The reported cases in this study were from an urban area, like as other Moroccan regions ([10,16,17]). In the same region, however, other study documented cases with a rural origin [9].

Food poisoning has particularly been reported in urban areas, where collective catering is more established than in rural regions, over the previous 10 years. However, we are beginning to notice that the rural environment is being affected as much, if not more so than the urban. The progress of the reporting system, as well as changing eating habits, such as the consumption of raw or lightly cooked food [18], can explain this.

The mean age was $28.6 \pm 17.8$ years. As a consequence, young adults were the most affected, which is consistent with the findings in other Moroccan regions $([9-11,16,19])$. This age group should be given special attention, with frequent monitoring of university residences and increased knowledge of appropriate food hygiene practices.

Females were more exposed than males, which is consistent with previous research $([9,10])$. Males, on the other side, were more affected than females in other regions [17]. This disparity can be explained by changes in eating patterns and the expansion of collective catering.

We observe in particular the predominance of cases in closed communities, which is consistent with the findings of other studies $([9,10])$. Therefore, collective catering would require regular monitoring, especially in school and university residences.

The high rate of cases requiring hospitalization emphasizes the severity of the poisoning. This rate calculated in this study $(40.5 \%)$ was higher than the national rate (32\%) according Moroccan Health Ministry [8]. Also, the global lethality rate in this study $(1.3 \%)$ was higher than the national rate $(0.4 \%)$.

Males were admitted to hospitals at a higher rate than females $\left(\mathrm{RR}=2.157\right.$, IC95\% [1.52 - 3.061], $\mathrm{X}^{2}=15.95, \mathrm{p}$ $<0.001)$, a finding that was also found in cases of urban origin $\left(\left(\mathrm{RR}=1.52, \mathrm{IC} 95 \%\right.\right.$ [0.8894 - 2.598], $\mathrm{X}^{2}=2.151$, $\mathrm{p}=0.07128)$. This indicates that food control and awareness programs in urban areas should be consolidated. 
Many bacterial pathogens, such as Salmonella, Campylobacter, Enterohaemorrhagic Escherichia coli, and Listeria monocytogenes, cause foodborne diseases, but norovirus and typhoid also produce significant disease burdens [5].

Furthermore, in this study, meat products were the first foodstuffs to be involved, accounting for $31 \%$ of each event, and the causal pathogen agent, Salmonella and Escherichia coli, were the most often isolated [20]. While fish and dairy product $([9,10,21])$, or vegetable dishes, and meat dishes [22] are the most commonly incriminated foods in other regions of Morocco, Staphylococcus aureus is the most usually isolated, and Clostridium perfringens [23]. In this study, samples for microbiological analysis were collected in only 6 of 11 events. This may be due to late reporting, or missing food remnants.

Food poisoning caused by fruits and fruit juices accounted for $28.7 \%$ of the cases in this research. The nature of the economic activity in this region, which is dominated by agriculture and the agri-food industry, might explain this conclusion. The prefectural laboratory of epidemiology and environmental hygiene in Agadir conducted the bacteriological analysis of these food poisoning cases. Specific food remnants are transferred to the National Institute of Hygiene in Rabat for toxicological investigation in some situations.

Pesticides are used irrationally in agriculture, putting the people at danger of acute toxicity( [24-26]). As a result, there is a need to improve food control at the local level through toxicological analysis, as well as to implement a pesticide monitoring strategy for agricultural pesticides.

More study is needed in this area to increase our understanding of food poisoning caused by agricultural pesticides.

Food laws, food control management (inspection services, laboratory services, food monitoring), epidemiological data management, awareness and training are all part of the national food control system [27].

Morocco has just undertaken a reorganization of the food safety control function, assigning it to a single agency [28]. In this context, professional training must keep pace with scientific advancements, particularly in the area of food safety.

The current research is a retrospective study with several limitations. Because of all the numerous variables in the incomplete survey forms, an information bias is possible. The results, however, can be used to better understand the epidemiological status of food poisoning in the Agadir Ida Outanane prefecture.

However, in order to fully use these findings, it is advised that the present epidemiological monitoring system be studied in order to get trustworthy data over a long period of time.

\section{Conclusion}

The food poisoning events related morbidity appears to be a major source of concern. However, because the available data is incomplete, this scenario should be regarded with caution at this time. We should point out that only the public sector reports food poisoning, and many events go unnoticed.

We need to develop and strengthen our monitoring system in order to better understand the epidemiology of food poisoning events. However, based on the results of this study, we may already adopt a preventative follow up to the region's unique characteristics and targeted at closed communities. Actions to be undertaken should focus on promoting good hygienic food practices.

\section{Acknowledgements}

We would like to express our gratitude to the professionals of Agadir's Prefectural Epidemiology Unit and the Environmental Health Unit for their assistance in compiling data on food poisoning events. We'd like to thank the professionals in charge at the regional level, the network service of health establishments, as well as the administrative and pedagogical staff at Agadir's Higher Institute of Nursing and Technical Health.

\section{References}

1. World Health Organization, editor, WHO Estimates of the Global Burden of Foodborne Diseases, Foodborne disease burden epidemiology reference group (2015)

2. World Health Organization, Food Saf. Fact Sheet (2019)

3. S. B. Duff, E. A. Scott, M. S. Mafilios, E. C. Todd, L. R. Krilov, A. M. Geddes, and S. J. Ackerman, J. Food Prot. 66, 2103 (2003)

4. J. F. Gruber, J. E. Bailey, and B. B. Kowalcyk, Foodborne Pathog. Dis. 12, 467 (2015)

5. A. H. Havelaar, M. D. Kirk, P. R. Torgerson, H. J. Gibb, T. Hald, R. J. Lake, N. Praet, D. C. Bellinger, N. R. de Silva, N. Gargouri, N. Speybroeck, A. Cawthorne, C. Mathers, C. Stein, F. J. Angulo, B. Devleesschauwer, and on behalf of World Health Organization Foodborne Disease Burden Epidemiology Reference Group, PLOS Med. 12, e1001923 (2015)

6. The poison control and pharmacovigilance center of Morocco, Ministry of Health, Toxicovigilance: general and specific reports for 2019 (Maroc, 2019), p. 16

7. R. Hajar, H. Hinde, O. Lahcen, H. Fatine, S. Abdelmajid, S.-B. Rachida, and M. Abdelghani, 14 (2013)

8. Ministry of Health, Morocco, Epidemiology and Public Health Bulletin (2017) 
9. M. Belomaria, A. O. T. Ahami, Y. Aboussaleh, B. Elbouhali, Y. Cherrah, and A. Soulaymani, Antropo (2007)

10. M. Belomaria, Y. Aboussaleh, A. O. T. Ahami, O. Bouazza, M. Mahly, and Y. Khayati, Antropo (2010)

11. N. Echahbi, A. Soulaymani, H. Hami, B. Benazzouz, L. Ouammi, A. Mokhtari, S. Achour, I. Semlali, and R. Soulaymani-Bencheikh, Bull. Société Pathol. Exot. 106, 48 (2013)

12. Moroccan Ministry of Interior, Wilaya of the Souss Massa Region, Prefecture of Agadir Ida Outanane, General Secretariat, Division of Economic Affairs and Coordination, (2013)

13. High-Commission for Planning, Rabat, Morocco, (2014)

14. AG. Dean, KM. Sullivan, and MM. Soe, OpenEpi: Open Source Epidemiologic Statistics for Public Health, Version 3.01 (2013)

15. M. Siham, A. Soulaymani, H. Hami, A. Mokhtari, D. Benali, and R. SoulaymaniBencheikh, Research fr1, (2014)

16. B. Oumokhtar, S. El Fakir, S. Maniar, and H. Sbai, Rev. DÉpidémiologie Santé Publique 57, S46 (2009)

17. B. El Bouhali, S. Belamalem, A. Bidi, N. Nekkal, I. Nasri, A. Mokhtari, A. Soulaymani, and M. Eddouks, Int. J. Innov. Appl. Stud. 8, 697 (2014)

18. L. Anelich, in Encycl. Food Saf. (Elsevier, 2014), pp. 262-275

19. H. Lamine, E. ouanouche, A. Soulaymani, and A. Khadmaoui, Food Poisoning and CareSeeking Behavior - Cases of Students from the City of Mohammedia in Morocco - Prospective Study (In Review, 2020)

20. B. Bouchrif, B. Paglietti, M. Murgia, A. Piana, N. Cohen, M. M. Ennaji, S. Rubino, and M. Timinouni, J. Infect. Dev. Ctries. 3, 035 (2009)

21. F. R. Filali, S. Benlarabi, R. Hmimou, R. Soulaymani-Bencheikh, M. Sefiani, and M. Boukili, J. Worlds Poult. Res. 9, 08 (2019)

22. N. E. Kadmiri, H. Bakouri, F. Bassir, S. Barmaki, L. Rachad, S. Nadifi, O. E. Kadmiri, and B. Amina, Pan Afr. Med. J. 24, (2016)

23. A. Ed-Dra, F. R. Filali, A. E. Allaoui, and A. Sfendla, Open Vet. J. 7, 323 (2017)

24. T. Eddaya, A. Boughdad, L. Becker, P. Chaimbault, and A. Zaïd, 10 (2015)

25. S. El Khaddam, S. Achour, A. Soulaymani, A. Mokhtari, and R. Soulaymani-Bencheikh, Arch. Pédiatrie 17, 96 (2010)

26. L. Lekhyar, N. Khadre, K. Bouayed, and N. Mikou, 2 (2020)

27. D. Faour-Klingbeil and E. C. D. Todd, Int. J. Environ. Res. Public. Health 17, 70 (2020)

28. H. Rachidi and $H$. Latrache, Rev. DÉpidémiologie Santé Publique 66, 153 (2018) 